\title{
ON STATISTICAL CONVERGENCE OF SEQUENCES OF FUNCTIONS IN 2-NORMED SPACES
}

\author{
SEVIM YegÜL AND ERDINÇ DÜNDAR
}

\begin{abstract}
Statistical convergence and statistical Cauchy sequence in 2 -normed space were studied by Gürdal and Pehlivan [M. Gürdal, S. Pehlivan, Statistical convergence in 2-normed spaces, Southeast Asian Bulletin of Mathematics, (33) (2009), 257-264]. In this paper, we get analogous results of statistical convergence and statistical Cauchy sequence of functions and investigate some properties and relationships between them in 2-normed spaces.
\end{abstract}

Mathematics subject classification (2010): 40A30, 40A35, 46A70.

Keywords and phrases: Statistical convergence, sequence of functions, statistical Cauchy sequence, 2-normed spaces.

\section{REFERENCES}

[1] V. Baláz, J. ČERveñanský, P. Kostyrko, T. S̆alát, I-convergence and I-continuity of real functions, Acta Mathematica, Faculty of Natural Sciences, Constantine the Philosopher University, Nitra, 5 (2004), 43-50.

[2] M. Balcerzak, K. Dems, A. Komisarski, Statistical convergence and ideal convergence for sequences of functions, J. Math. Anal. Appl. 328(1) (2007), 715-729.

[3] H. ÇaKalli AND S. ERSAN, New types of continuity in 2-normed spaces, Filomat 30 (3) (2016), $525-532$.

[4] E. DÜNDAR, B. AltaY, $\mathscr{I}_{2}$-convergence of double sequences of functions, Electronic Journal of Mathematical Analysis and Applications 3 (1) (2015), 111-121.

[5] E. DÜNDAR, B. Altay, $\mathscr{I}_{2}$-uniform convergence of double sequences of functions, Filomat 30 (5) (2016), 1273-1281.

[6] E. DüNDAR, On some results of $\mathscr{I}_{2}$-convergence of double sequences of functions, Mathematical Analysis Sciences and Applications E-notes 3 (1) (2015), 44-52.

[7] H. FAST, Sur la convergence statistique, Colloq. Math. 2 (1951), 241-244.

[8] J. A. FRIDY, On statistical convergence, Analysis 5 (1985), 301-313.

[9] S. GÄHLER, 2-metrische Räume und ihre topologische struktur, Math. Nachr. 26 (1963), 115-148.

[10] S. GÄHLER, 2-normed spaces, Math. Nachr. 28 (1964), 1-43.

[11] F. Gezer, S. KARAKUŞ, I and $\mathscr{I}^{*}$ convergent function sequences, Math. Commun. 10 (2005), $71-80$.

[12] A. GÖKhan And M. GÜNGÖR, On pointwise statistical convergence, Indian J. Pure Appl. Math. 33 (9) (2002), 1379-1384.

[13] A. GÖKHAN, M. GÜNGÖR AND M. ET, Statistical convergence of double sequences of real-valued functions, Int. Math. Forum, 2 (8) (2007), 365-374.

[14] H. Gunawan, M. Mashadi, On finite dimensional 2-normed spaces, Soochow J. Math. 27 (3) (2001), 321-329.

[15] M. GÜRdal, S. Pehlivan, The statistical convergence in 2-Banach spaces, Thai J. Math. 2 (1) (2004), 107-113.

[16] M. GÜRDAL, S. Pehlivan, Statistical convergence in 2-normed spaces, Southeast Asian Bulletin of Mathematics 33(2) (2009), 257-264.

[17] M. GÜRDAL, I. AÇıK, On I I-Cauchy sequences in 2-normed spaces, Math. Inequal. Appl. 11 (2) (2008), 349-354. 
[18] M. GÜRDAL, On ideal convergent sequences in 2-normed spaces, Thai J. Math. 4 (1) (2006), 85-91.

[19] M. Murs Aleen, S. A. Mohiuddine, On ideal convergence in probabilistic normed spaces, Math. Slovaca 62 (1) (2012), 49-62.

[20] M. Mursaleen, A. Alotaibi, On $\mathscr{I}$-convergence in random 2-normed spaces, Math. Slovaca 61 (6) (2011), 933-940.

[21] S. SARABADAN, S. TALEBI, Statistical convergence and ideal convergence of sequences of functions in 2-normed spaces, Internat. J. Math. Math. Sci. 2011 (2011), 10 pages, doi:10.1155/2011/517841.

[22] E. S AVAŞ, M. GÜRDAL, Ideal Convergent Function Sequences in Random 2-Normed Spaces, Filomat, 30 (3) (2016), 557-567.

[23] I. J. Schoenberg, The integrability of certain functions and related summability methods, Amer. Math. Monthly 66 (1959), 361-375.

[24] A. Sharma, K. Kumar, Statistical convergence in probabilistic 2-normed spaces, Mathematical Sciences, 2 (4) (2008), 373-390.

[25] A. ŞAhineR, M. GÜRdAL, S. SAltan, H. Gunawan, Ideal convergence in 2-normed spaces, Taiwanese J. Math. 11(5) (2007), 1477-1484. 